\title{
FRAGILIDADE AMBIENTAL NOS PICOS CAMACUÃ, CAMAPUÃ E TUCUM, CAMPINA GRANDE DO SUL, PR
}

\author{
Yury Vashchenko*, Nerilde Favaretto**, Daniela Biondi*** \\ *Eng. Florestal, M.Sc. - vashchenko_01@yahoo.com.br \\ **Enga . Agrônoma, PhD., Depto. de Solos e Engenharia Agrícola, UFPR - nfavaretto@ufpr.br \\ ***Eng ${ }^{\text {a }}$. Florestal, Dr ${ }^{\mathrm{a}}$., Depto. de Ciências Florestais, UFPR - dbiondi@ufpr.br \\ Recebido para publicação: 28/08/2006 - Aceito para publicação: 23/11/2006
}

\begin{abstract}
Resumo
O objetivo deste estudo foi caracterizar e avaliar a fragilidade ambiental dos picos Camacuã, Camapuã e Tucum, situados na Serra do Mar paranaense, no município de Campina Grande do Sul. A fragilidade ambiental foi determinada conforme a metodologia de Ross (1994), baseada em dados de declividade, solo e vegetação atual. O cruzamento do mapa da declividade com o mapa de solos gerou o mapa de fragilidade potencial e o cruzamento do mapa da fragilidade potencial com o mapa da vegetação gerou o mapa de fragilidade emergente. A fragilidade potencial em $92 \%$ da área total foi classificada como muito alta, enquanto que $54 \%$ e $40 \%$ da área apresentaram fragilidade emergente média e alta, respectivamente. A área estudada é potencialmente muito frágil devido à declividade acentuada predominante e aos solos pouco desenvolvidos. No entanto, a cobertura vegetal exerce um papel fundamental na proteção contra a degradação, amenizando a fragilidade potencial.

Palavras-chave: Uso recreativo; declividade; cobertura vegetal; solo; degradação.
\end{abstract}

\begin{abstract}
Environmental fragility of the peaks Camacuã, Camapuã and Tucum, Campina Grande do Sul, PR. The objective of this study was to characterize and to evaluate the environmental fragility of the peaks Camacuã, Camapuã and Tucum, Campina Grande do Sul, PR. The environmental fragility was determined according to Ross (1994) method, based on the slope, soil, and vegetation. The overlapping of the slope map on the soil map generated the potential fragility map and the overlapping of the potential fragility map on the vegetation map generated the emergent fragility map. The potential fragility in $92 \%$ of the total area was classified as very high, while $54 \%$ and $40 \%$ of the area presented medium and high emergent fragility, respectively. The studied area is very fragile due to the high slope and to the poorly developed soils. However the existing vegetation in the area is fundamental to protect it against the degradation, decreasing the potential fragility.

Keywords: Recreational use; slope; vegetation; soil; degradation.
\end{abstract}

\section{INTRODUÇ̃̃O}

Os sistemas ambientais, em face das intervenções humanas, apresentam maior ou menor fragilidade em função de suas características "genéticas". Qualquer alteração nos diferentes componentes da natureza (relevo, solo, vegetação, clima e recursos hídricos) acarreta o comprometimento da funcionalidade do sistema, quebrando o seu estado de equilíbrio dinâmico. Essas variáveis, tratadas de forma integrada, possibilitam obter um diagnóstico das diferentes categorias hierárquicas da fragilidade dos ambientes naturais. Estudos relativos às fragilidades dos ambientes são de extrema importância ao planejamento ambiental, pois sua identificação proporciona uma melhor definição das diretrizes e ações a serem implantadas no espaço físico-territorial, servindo de base para o zoneamento e fornecendo subsídios à gestão do território (SPÖRL; ROSS, 2004).

Segundo Ross (1994), as unidades de fragilidade dos ambientes naturais devem ser resultantes dos levantamentos básicos de geomorfologia, solos, cobertura vegetal/uso da terra e clima. Esses elementos tratados de forma integrada possibilitam obter um diagnóstico das diferentes categorias hierárquicas da fragilidade. 
A ocorrência de impactos em áreas naturais é conseqüência do uso, seja ele realizado com objetivos educacionais, seja com objetivos recreativos. Todos os visitantes, inclusive os com maior consciência ecológica, causam impacto (BARROS, 2003). Entre os usos recreativos, encontra-se a prática do montanhismo, envolvendo a formação de trilhas, as quais passam pelas mais diversas situações de relevo, solo e vegetação. A primeira conseqüência na formação de uma trilha é a eliminação da cobertura vegetal, que protege o solo do impacto direto das gotas da chuva e do escorrimento superficial, causando alterações nas propriedades físicas do solo. No entanto, a pressão exercida pela prática de caminhadas pode causar impactos diferentes dependendo da condição existente. Por exemplo, algumas plantas são mais resistentes do que outras ao pisoteio e solos menos desenvolvidos resistem menos ao processo de compactação e à erosão.

Por mais que o uso de trilhas e de acampamentos cause menor degradação que o uso agrícola ou pastoril, é importante avaliar a fragilidade desses ecossistemas para planejar um uso recreativo menos impactante, bem como para subsidiar zoneamentos de unidades de conservação e outros tipos de áreas naturais protegidas. Assim, o objetivo deste trabalho foi caracterizar e avaliar a fragilidade ambiental dos picos Camacuã, Camapuã e Tucum, os quais vêm sendo utilizados na prática do montanhismo.

\section{MATERIAL E MÉTODOS}

\section{Caracterização da área de estudo}

A Serra do Mar constitui um sistema montanhoso que se estende desde o Espírito Santo até o sul de Santa Catarina. No estado do Paraná, é a zona limítrofe entre o litoral e o Primeiro Planalto, formando serras marginais descontínuas, que se elevam de $500 \mathrm{~m}$ a $900 \mathrm{~m}$ acima do nível do planalto, sendo mais escarpada do lado do Atlântico que do continental e dotada de taludes íngremes e vertentes vigorosas (BIGARELLA, 1978).

No Paraná, parte da Serra do Mar compõe a Área Especial de Interesse Turístico (AEIT) do Marumbi, que engloba diversas serras. Nos municípios de Antonina e Campina Grande do Sul, está localizada a Serra Ibitiraquire (Serra Verde, em tupi). Na parte que compreende o município de Campina Grande do Sul, na localidade denominada Terra Boa (entre as coordenadas $712.000 \mathrm{~m} \mathrm{e} 718.000 \mathrm{~m} \mathrm{~W}$ e 7.203.500 m e 7.206.500 m S no sistema UTM, Fuso 22 sul, Meridiano Central 51 ${ }^{\circ} 00$ '00"), estão localizados os picos Camacuã, Camapuã e Tucum $(1.550 \mathrm{~m}, 1.706 \mathrm{~m}$ e $1.736 \mathrm{~m}$ de altitude, respectivamente), componentes do Parque Estadual do Pico Paraná, o qual foi criado em 2002 por decreto estadual, porém ainda não implantado (Figura 1). O acesso a esses picos é feito pela rodovia BR-116, saindo de Curitiba e percorrendo aproximadamente $50 \mathrm{~km}$ até a localidade de Terra Boa, onde se percorrem cerca de $5 \mathrm{~km}$ em uma estrada, chegando a uma chácara (chácara do Milani), onde a trilha de acesso aos picos tem início.

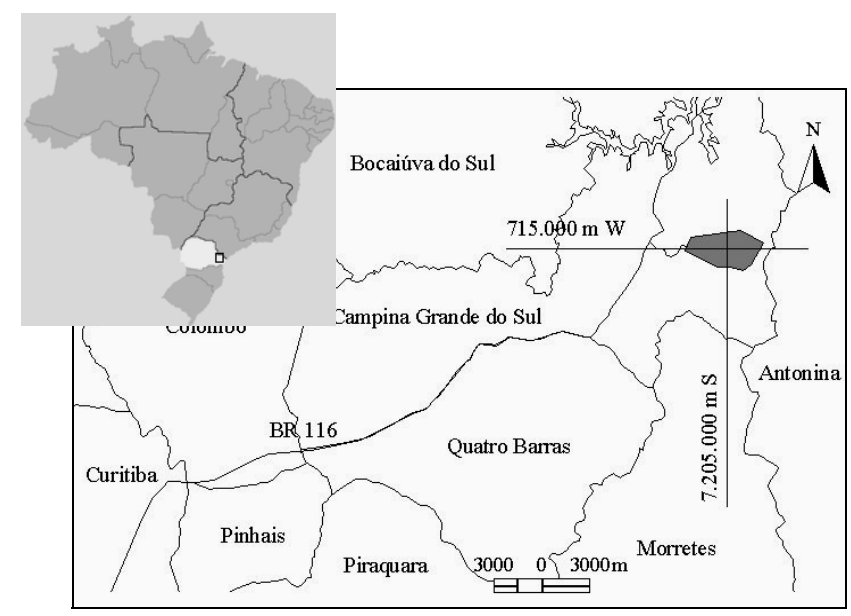

Figura 1. Localização da área de estudo.

Figure 1. Localization of the study area. 
Segundo a classificação de Köppen, o clima é temperado - $\mathrm{Cfb}$-, caracterizado por temperatura média no mês mais frio abaixo de $18{ }^{\circ} \mathrm{C}$ (mesotérmico), com verões frescos, temperatura média no mês mais quente abaixo de $22^{\circ} \mathrm{C}$ e sem estação seca definida (IAPAR, 1994).

A área encontra-se sobre um bloco granítico, denominado Granito Graciosa, rocha intrusiva originada a mais de 600 milhões de anos, no Pré-Cambriano, a qual é retalhada por sistemas de fendas, diáclases e falhamentos (CORDANI; GIRARDI, 1967).

\section{Caracterização da fragilidade ambiental}

Para caracterizar a fragilidade ambiental dos picos Camacuã, Camapuã e Tucum, utilizou-se a metodologia de Ross (1994), baseada em dados de declividade, solo e vegetação atual. O cruzamento do mapa de declividade com o mapa de solos gerou o mapa de fragilidade potencial, e o cruzamento do mapa da fragilidade potencial com o mapa da vegetação atual gerou o mapa de fragilidade emergente. A seguir está descrito o procedimento de obtenção de cada mapa.

\section{a) Mapa de declividade}

Inicialmente foi elaborado o mapa planialtimétrico da área de estudo, a partir da interpretação dos mapas planialtimétricos da Represa do Capivari, escala 1:50.000 (BRASIL, 1971), de Morretes, escala 1:50.000 (IBGE, 1992a), e de observações do relevo em campo. Com a utilização de um "scanner", as informações desses mapas planialtimétricos foram passadas para o meio digital em forma de arquivos TIFF. Esses arquivos foram georreferenciados no programa ENVI 3.2. No programa ArcView GIS 3.2, foi realizada a digitalização das curvas de nível e da drenagem, sendo então gerado o mapa planialtimétrico da área.

O mapa da declividade foi elaborado a partir do mapa planialtimétrico, através do programa SPRING 4.1, sendo dividido nas seguintes classes: 0 a $6 \%, 6$ a $12 \%, 12$ a $20 \%, 20$ a $30 \%$ e $>30 \%$, de acordo com Ross (1994).

\section{b) Mapa de solos}

Os solos foram classificados de acordo com EMBRAPA (1999) a partir de levantamento de campo e análise em laboratório. O mapa de solos da área dos picos Camacuã, Camapuã e Tucum foi gerado levando em consideração as classes obtidas a partir de tradagens, abertura de trincheiras e os limites da vegetação. Cada classe de solo foi delimitada pelo tipo de vegetação, devido à alta relação entre ambos. Maiores detalhes sobre a classificação do solo podem ser encontrados em Vashchenko (2006).

\section{c) Mapa da vegetação}

O mapeamento da vegetação foi realizado a partir do mapa digital da vegetação obtido de SEMA (2002), da comparação com fotografias aéreas da área tiradas em 1980, com escala 1:30.000, e do reconhecimento em campo através da observação das características fisionômicas da vegetação ao longo da trilha. A classificação da vegetação original foi de acordo com IBGE (1992b), e da secundária, de acordo com SEMA (1998).

\section{d) Mapa da fragilidade potencial}

Para a análise da fragilidade potencial, foi gerada uma tabela matriz (Tabela 1) com as classes de solo e declividade, utilizando-se a média aritmética da fragilidade dos fatores solo e declividade, os quais tiveram pesos equivalentes, para representar a fragilidade potencial, de acordo com Almeida (2003). Por não haver diferenças geológicas e climáticas na área, esses fatores não foram considerados na análise da fragilidade.

Adaptado da metodologia de Ross (1994), os solos foram classificados considerando-se a sua fragilidade ou suscetibilidade à erosão (Tabela 1). Dessa forma, o CAMBISSOLO HÁPLICO Ta Distrófico lítico foi enquadrado na classe alta (4), devido à maior suscetibilidade à erosão quando comparado com solos de outros grupos considerados mais desenvolvidos. O grupo dos Cambissolos é menos suscetível à erosão apenas em relação ao grupo dos Neossolos. Assim, o NEOSSOLO LITÓLICO Distrófico típico e o NEOSSOLO LITÓLICO Hístico típico + AFLORAMENTO DE ROCHA foram enquadrados na classe muito alta (5), por serem os solos menos desenvolvidos e mais suscetíveis à erosão. Como o CAMBISSOLO HÁPLICO Ta Distrófico léptico apresenta a inclusão do NEOSSOLO 
LITÓLICO Húmico típico, tomou-se como referência o solo mais restritivo (o Neossolo), fazendo com que o referido Cambissolo fosse enquadrado como fragilidade muito alta (5).

De acordo com a metodologia de Ross (1994), baseado na intensidade dos processos erosivos e dos riscos de escorregamentos/deslizamentos, as declividades foram separadas em cinco categorias hierárquicas, 0 a $6 \%, 6$ a $12 \%, 12$ a $20 \%, 20$ a $30 \%$ e > $30 \%$, classificadas como muito baixa (1), baixa (2), média (3), alta (4) e muito alta (5), respectivamente (Tabela 1).

$\mathrm{Na}$ elaboração do mapa de fragilidade potencial, utilizou-se a ferramenta LEGAL (Linguagem Espacial de Geoprocessamento Algébrico) do programa SPRING 4.1, com a qual se efetuou o cruzamento dos mapas de declividade e solos, considerando os valores da tabela 1. O mapa de fragilidade potencial foi finalizado no programa ArcView GIS 3.2.

Tabela 1. Definição da fragilidade potencial dos picos Camacuã, Camapuã e Tucum através dos dados de solos e declividade.

Table 1. Definition of the potential fragility of the Camacuã, Camapuã, and Tucum peaks by soil and slope data.

\begin{tabular}{|c|c|c|c|c|c|c|}
\hline \multirow[b]{2}{*}{ Classe de solo } & & \multicolumn{5}{|c|}{ Classe de declividade } \\
\hline & & $\begin{array}{l}0 \text { a } 6 \% \\
1 \text { (MB) }\end{array}$ & $\begin{array}{l}6 \text { a } 12 \% \\
2 \text { (B) }\end{array}$ & $\begin{array}{c}12 \text { a } 20 \% \\
3(\mathrm{M})\end{array}$ & $\begin{array}{c}20 \text { a } 30 \% \\
4(\mathrm{~A})\end{array}$ & $\begin{array}{l}>30 \% \\
5 \text { (MA) }\end{array}$ \\
\hline $\begin{array}{l}\text { CAMBISSOLO HÁPLICO Ta } \\
\text { Distrófico lítico }\end{array}$ & $4(\mathrm{~A})$ & $(2,5) 3$ & (3) 3 & $(3,5) 4$ & (4) 4 & $(4,5) 5$ \\
\hline $\begin{array}{l}\text { NEOSSOLO LITÓLICO } \\
\text { Distrófico típico }\end{array}$ & 5 (MA) & (3) 3 & $(3,5) 4$ & (4) 4 & $(4,5) 5$ & (5) 5 \\
\hline $\begin{array}{l}\text { CAMBISSOLO HÁPLICO Ta } \\
\text { Distrófico léptico }\end{array}$ & 5 (MA) & (3) 3 & $(3,5) 4$ & (4) 4 & $(4,5) 5$ & (5) 5 \\
\hline $\begin{array}{l}\text { NEOSSOLO LITÓLICO Hístico } \\
\text { típico + AFLORAMENTO DE } \\
\text { ROCHA }\end{array}$ & 5 (MA) & (3) 3 & $(3,5) 4$ & (4) 4 & $(4,5) 5$ & (5) 5 \\
\hline
\end{tabular}

Fonte: Adaptado de Ross (1994)

Nota: Fragilidade em relação à declividade e solo: $(\mathrm{MB})$ - muito baixa, $(\mathrm{B})$ - baixa, $(\mathrm{M})$ - média, $(\mathrm{A})$ - alta, (MA) - muito alta. Fragilidade Potencial: 3 - média, 4 - alta, 5 - muito alta. Em números decimais, efetuou-se o arredondamento para cima em função da alta fragilidade dos solos.

\section{e) Mapa da fragilidade emergente}

Para a análise da fragilidade emergente, foi gerada uma matriz (Tabela 2) a partir das classes da fragilidade potencial e da vegetação atual. Foi utilizada a média aritmética da fragilidade potencial e da cobertura vegetal, com peso equivalente, para representar a fragilidade emergente, conforme Almeida (2003).

Baseado em perda de solo por tipo de cultivo, Ross (1994) estabeleceu o grau de proteção aos solos pela cobertura vegetal e definiu classes de fragilidade ou graus de proteção de acordo com o tipo de cobertura. Seguindo a classificação de Ross (1994), para as florestas Ombrófila Mista Montana, Ombrófila Densa Montana e Ombrófila Densa Altomontana, atribui-se o grau de proteção muito alto (1), e para o Refúgio Vegetacional e as fases inicial e intermediária da sucessão secundária, o grau de proteção alto (2) (Tabela 2).

Na elaboração do mapa da fragilidade emergente, utilizou-se a ferramenta LEGAL do programa SPRING 4.1, com o qual se efetuou o cruzamento dos mapas da fragilidade potencial e vegetação atual, considerando-se os valores da tabela 2 . O mapa de fragilidade emergente foi finalizado no programa ArcView GIS 3.2.

\section{RESULTADOS E DISCUSSÃO}

\section{Relevo}

A altitude na área de estudo varia de 880 a $1.736 \mathrm{~m}$, sendo o ponto culminante o pico Tucum. Ao observar as figuras 2 e 3 e a tabela 3, nota-se que se trata de um relevo montanhoso, sendo que $71 \%$ da área apresentam declividade acima de $30 \%, 21 \%$ da área entre 20 e $30 \%$ e apenas $8 \%$ da área apresentam declividade abaixo de $20 \%$. Esses resultados indicam um elevado potencial de degradação (fragilidade potencial), devido à grande influência da declividade nos processos erosivos do solo. Um desses processos (erosão hídrica) pode ser desencadeado pelo volume de chuva e a ausência de cobertura vegetal na superfície do solo. 
Tabela 2. Definição da fragilidade emergente dos picos Camacuã, Camapuã e Tucum através dos dados de vegetação atual versus fragilidade potencial.

Table 2. Definition of the emergent fragility of the Camacuã, Camapuã, and Tucum peaks by existing vegetation versus potential fragility data.

\begin{tabular}{lcccc}
\hline \multirow{2}{*}{ Vegetação atual } & \multirow{2}{*}{ Grau de proteção } & \multicolumn{3}{c}{ Fragilidade potencial } \\
\cline { 3 - 5 } & & $\mathbf{3}$ (Média) & 4 (Alta) & $\mathbf{5}$ (Muito alta) \\
\hline Floresta Ombrófila Densa Montana & 1 (Muito Alto) & $(2) 2$ & $(2,5) 2$ & $(3) 3$ \\
Floresta Ombrófila Mista Montana & 1 (Muito Alto) & $(2) 2$ & $(2,5) 2$ & $(3) 3$ \\
Floresta Ombrófila Densa Altomontana & 1 (Muito Alto) & $(2) 2$ & $(2,5) 3$ & $(3) 3$ \\
Refúgio Vegetacional & 2 (Alto) & $(2,5) 2$ & $(3) 3$ & $(3,5) 4$ \\
Sucessão secundária inicial & 2 (Alto) & $(2,5) 2$ & $(3) 3$ & $(3,5) 4$ \\
Sucessão secundária intermediária & 2 (Alto) & $(2,5) 2$ & $(3) 3$ & $(3,5) 4$ \\
\hline
\end{tabular}

Fonte: Adaptado de Ross (1994)

Nota: Fragilidade Emergente: 2 - Baixa, 3 - Média e 4 - Alta. Em números decimais, efetuou-se o arredondamento para cima na fragilidade maior que 3 e para baixo na fragilidade menor que 3 .

Segundo Cogo e Bertol (1998), os fatores controladores da erosão hídrica do solo podem ser separados em: erosividade da chuva (capacidade potencial da chuva em causar erosão) e erodibilidade do solo (suscetibilidade à erosão). A erodibilidade do solo depende de suas características intrínsecas (físicas, químicas e biológicas), da topografia, da cobertura do solo e das práticas conservacionistas. Quanto à topografia, o que mais influencia é o comprimento, grau e forma do declive. Numa encosta, quanto maior o comprimento e o grau de declive, maior o volume da enxurrada, porém a erosão é mais influenciada pelo grau de declividade do que pelo comprimento da pendente. A forma do declive também influencia a erosão hídrica, sendo que, de maneira geral, as perdas de solo são maiores nos declives convexos, intermediárias nos uniformes e menores nos côncavos.

Além desses, há o efeito da declividade na erosão, que é decorrente do aumento da velocidade e volume da enxurrada, que pode ser influenciada pela baixa cobertura superficial. Nessas condições, o solo fica sujeito à formação de sulcos, selos e/ou crostas, os quais dificultam a infiltração de água, favorecendo o escoamento superficial (COGO et al., 2003).

Tabela 3. Área (em ha e \%) de cada classe de declividade nos picos Camacuã, Camapuã e Tucum.

Table 3. Area (ha and \%) of each slope class in the Camacuã, Camapuã, and Tucum peaks.

\begin{tabular}{|c|c|c|}
\hline \multirow{2}{*}{$\begin{array}{c}\text { Classe de declividade } \\
(\%)\end{array}$} & \multicolumn{2}{|c|}{ Área } \\
\hline & (ha) & $(\%)$ \\
\hline 0 a 6 & 16 & 2,0 \\
\hline 6 a 12 & 13 & 1,6 \\
\hline 12 a 20 & 35 & 4,4 \\
\hline 20 a 30 & 166 & 20,6 \\
\hline$>30$ & 575 & 71,4 \\
\hline Total & & \\
\hline
\end{tabular}

Solos

$\mathrm{Na}$ área foram identificadas cinco classes de solo, sendo três pertencentes ao grupo dos Neossolos e dois ao grupo dos Cambissolos. Na figura 4 podem ser observados distintamente dois Cambissolos e dois Neossolos. O terceiro Neossolo, classificado como NEOSSOLO LITÓLICO Húmico típico, encontrado no fundo do vale, acompanhando o ribeirão Samambaia, foi considerado como inclusão no CAMBISSOLO HÁPLICO Ta Distrófico léptico e no NEOSSOLO LITÓLICO Distrófico típico. A maior parte da área é ocupada pelo NEOSSOLO LITÓLICO Distrófico típico, que corresponde a $49,7 \%$ (Tabela 4$)$.

A profundidade dos Neossolos chegou até $25 \mathrm{~cm}$, enquanto que a dos Cambissolos chegou a ultrapassar os $50 \mathrm{~cm}$. A profundidade dos horizontes em cada solo oscilou muito, em alguns pontos passando de $20 \mathrm{~cm}$, e em outros sendo menor que $10 \mathrm{~cm}$. Isso possivelmente ocorreu devido ao relevo e à precipitação abundante, fatores que interferem na formação do solo. 


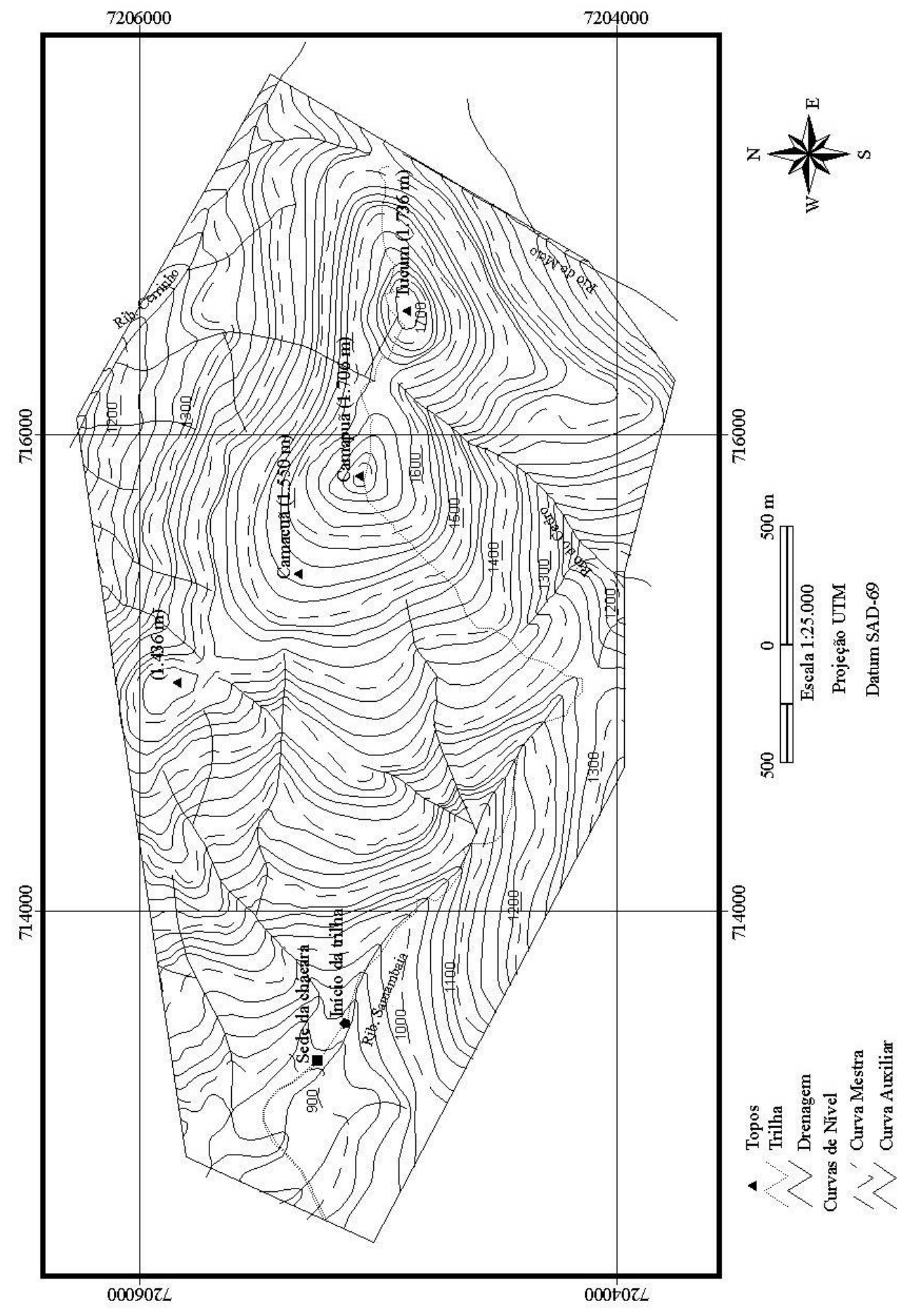

Figura 2. Mapa planialtimétrico dos picos Camacuã, Camapuã e Tucum. Figure 2. Topographic map of the Camacuã, Camapuã and Tucum peaks. 


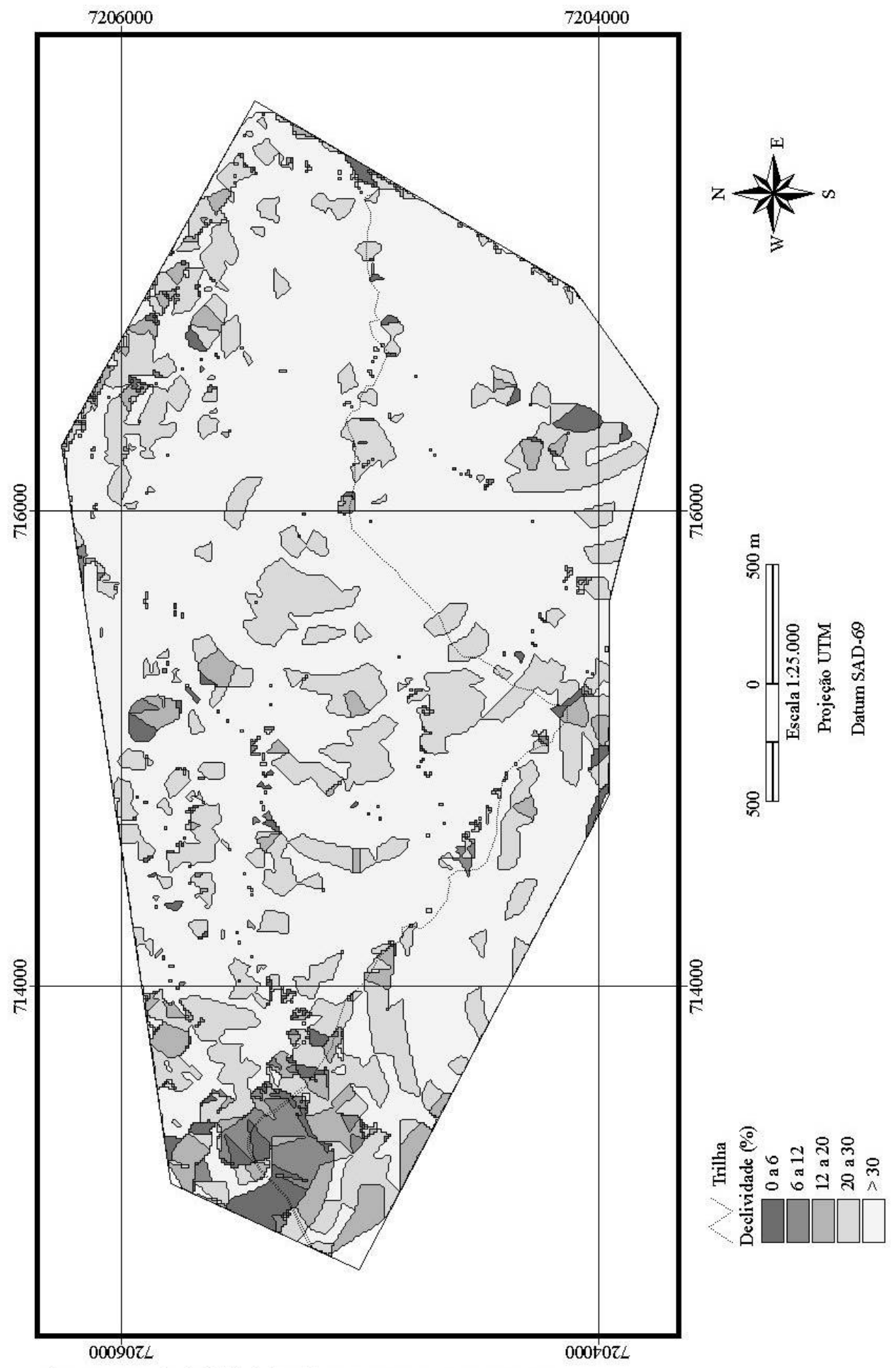

Figura 3. Mapa de declividade dos picos Camacuã, Camapuã e Tucum. Figure 3. Slope map class of the Camacuã, Camapuã and Tucum peaks. 


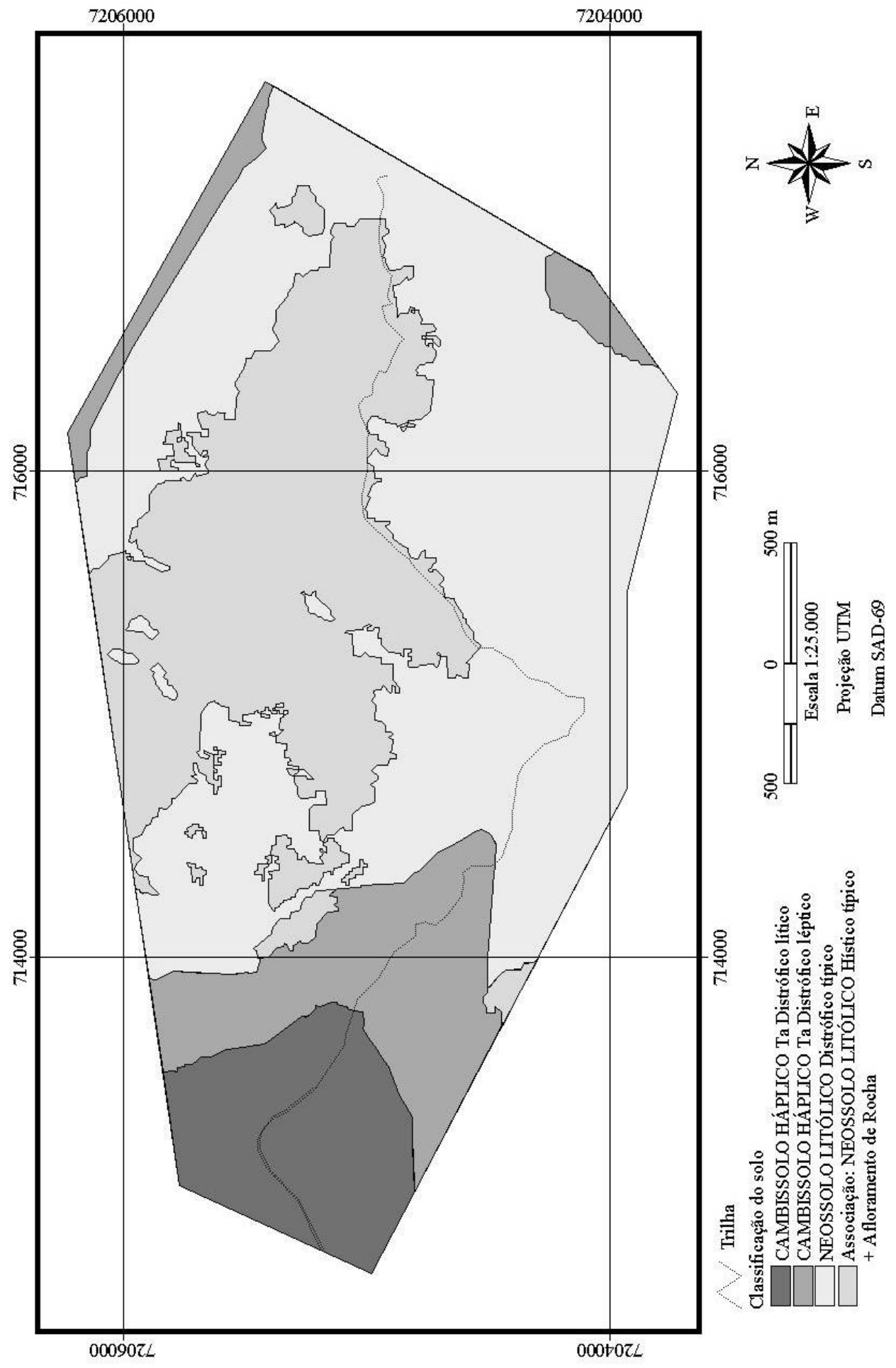

Figura 4. Mapa de solos dos picos Camacuã, Camapuã e Tucum.

Figure 4. Soil map class of the Camacuã, Camapuã and Tucum peaks. 


\section{Vegetação}

A área de estudo é coberta por duas florestas distintas, a Floresta Ombrófila Densa, também conhecida como Floresta Atlântica, e a Floresta Ombrófila Mista, também conhecida como Floresta com Araucária, sendo que ocorre a formação Montana na Floresta Ombrófila Mista e as formações Montana e Altomontana na Floresta Ombrófila Densa. Além das florestas Ombrófila Densa e Mista, a área apresenta os Refúgios Vegetacionais, os quais estão localizados nos topos.

Tabela 4. Área (em ha e \%) de cada classe de solo nos picos Camacuã, Camapuã e Tucum.

Table 4. Area (ha and \%) of each soil class in the Camacuã, Camapuã, and Tucum peaks.

\begin{tabular}{lcc}
\hline \multirow{2}{*}{ Classe dos solos (EMBRAPA, 1999) } & \multicolumn{2}{c}{ Área } \\
\cline { 2 - 3 } CAMBISSOLO HÁPLICO Ta Distrófico lítico & (ha) & $\mathbf{( \% )}$ \\
CAMBISSOLO HÁPLICO Ta Distrófico léptico & 75 & 9,4 \\
NEOSSOLO LITÓLICO Distrófico típico & 105 & 13,0 \\
NEOSSOLO LITÓLICO Hístico típico + AFLORAMENTO DE ROCHA & 400 & 49,7 \\
\hline Total & 224 & 27,8 \\
\hline
\end{tabular}

Em campo, observou-se uma alta relação entre o solo e a vegetação. Possivelmente, a vegetação seja reflexo das classes de solo existentes, sendo que, quanto mais desenvolvido o solo, mais desenvolvida a vegetação sobre ele. Sobre o NEOSSOLO LITÓLICO Hístico típico foi constatado o predomínio dos Refúgios Vegetacionais (campos de altitude), enquanto que sobre o NEOSSOLO LITÓLICO Distrófico típico foi constatado o predomínio da Floresta Ombrófila Densa Altomontana. Sob a Floresta Ombrófila Densa Montana e a Floresta Ombrófila Mista Montana foi observada a predominância do CAMBISSOLO HÁPLICO Ta Distrófico léptico e do CAMBISSOLO HÁPLICO Ta Distrófico lítico, respectivamente. Como o NEOSSOLO LITÓLICO Húmico típico aparece apenas como inclusão, aparentemente ele não influi na vegetação. No entanto, apesar de não estar no mapa, observou-se a existência da Floresta Ombrófila Densa Montana e da Floresta Ombrófila Densa Altomontana sobre esse solo.

$\mathrm{Na}$ figura 5 está apresentado o mapa da vegetação atual, podendo ser observados o remanescente da vegetação original e as áreas de vegetação secundária, que ocorrem principalmente no vale do ribeirão Samambaia. As fases de sucessão secundária inicial e de sucessão secundária intermediária ocorrem tanto na Floresta Ombrófila Mista Montana como na Floresta Ombrófila Densa, no entanto, no presente trabalho, não se determinou qual a contribuição individual delas nas respectivas sucessões secundárias. Conforme análise das fotografias aéreas, a sucessão secundária foi conseqüência de um uso agrícola que ocorreu anteriormente a 1980.

A sucessão secundária cobre apenas $19 \%$ da área, sendo que $81 \%$ da área permanecem cobertas pela vegetação original. A Floresta Ombrófila Densa Altomontana cobre a maior parte da área $(43,7$ \%), conforme tabela 5 .

Em campo, observou-se que o Refúgio Vegetacional sobre o pico Camacuã vem sofrendo uma invasão por pinus (Pinus sp). Essa invasão ainda não alterou completamente a característica do refúgio, pois as árvores de pinus estão dispersamente distribuídas no local, porém, representa uma ameaça futura. Ainda em campo, foram observados indícios de queimadas, na borda das florestas, como por exemplo a existência de árvores emergentes da floresta atual, ou seja, árvores que sobreviveram às queimadas. Essas queimadas aparentemente favoreceram a expansão da área do Refúgio Vegetacional (Figura 5).

Tabela 5. Área (em ha e \%) ocupada pela vegetação atual nos picos Camacuã, Camapuã e Tucum. Table 5. Area (ha and \%) of the existing vegetation in the Camacuã, Camapuã, and Tucum peaks.

\begin{tabular}{lcc}
\hline \multirow{2}{*}{ Vegetação atual } & \multicolumn{2}{c}{ Área } \\
\cline { 2 - 3 } & (ha) & $\mathbf{\%}$ \\
\hline Sucessão Secundária Intermediária & 79 & 9,8 \\
Sucessão Secundária Inicial & 78 & 9,7 \\
Floresta Ombrófila Mista Montana & 13 & 1,6 \\
Floresta Ombrófila Densa Montana & 57 & 7,1 \\
Floresta Ombrófila Densa Altomontana & 352 & 43,7 \\
Refúgio Vegetacional & 226 & 28,1 \\
\hline Total & 805 & 100,0 \\
\hline
\end{tabular}




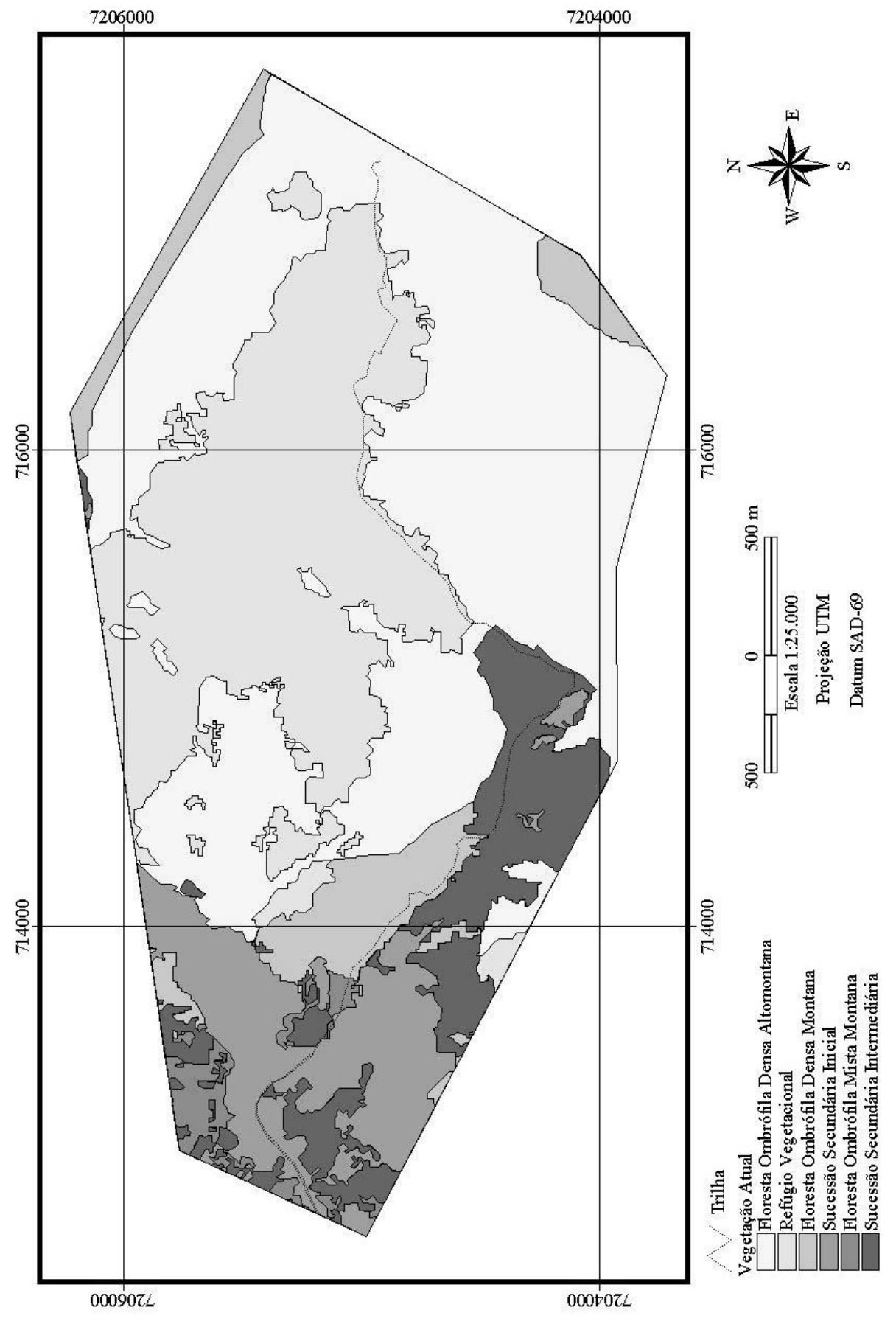

Figura 5. Mapa de vegetação atual dos picos Camacuã, Camapuã e Tucum.

Figure 5. Existing vegetation map of the Camacuã, Camapuã and Tucum peaks.

\section{Fragilidade ambiental}

\section{a) Fragilidade potencial}

Como pode ser visto na figura 6 , as classes de fragilidade potencial definidas para a área de estudo foram: média (3), alta (4) e muito alta (5), sendo que $92 \%$ da área foram classificados como muito alta (5) e o restante da área foi classificado como alta e média (Tabela 6). 
Essa elevada fragilidade potencial deve-se tanto à declividade acentuada como à presença de solos altamente suscetíveis ao processo erosivo. Os solos (Figura 4 e Tabela 4) foram determinantes para uma classe de fragilidade potencial mais elevada mesmo nas áreas com menor declividade, pois, segundo Ross (1994), os Cambissolos possuem um grau de fragilidade alto (4), enquanto que os Neossolos possuem um grau de fragilidade muito alto (5), e, portanto, mesmo em declividades entre 0 e $6 \%$ (classe 1 - fragilidade muito baixa) a fragilidade potencial foi média (3) (Tabela 1). Em relação à declividade, predominaram, em $71 \%$ da área, declividades acima de $30 \%$ (classe 5 - fragilidade muito alta) (Tabela 3).

Considerando a mesma metodologia, ou seja, analisando os fatores solo e declividade, na avaliação da fragilidade de acordo com Ross (1994), outros autores observaram resultados semelhantes aos aqui apresentados. Ghezzi (2003), ao avaliar a fragilidade ambiental da bacia do rio Xaxim, em Morretes (PR), e Almeida (2003), ao analisar a fragilidade ambiental no município de Colombo (PR), classificaram a fragilidade potencial nos locais de maior declividade, acima de $30 \%$, com presença de Cambissolos ou Neossolos também como muito alta (5). Da mesma forma, baseado na metodologia de Ross (1994), porém utilizando outros fatores além de solos e declividade, Floriani (2003) avaliou as microbacias hidrográficas de Fervida e de Rio das Onças, localizadas em Colombo (PR), e encontrou predomínio de fragilidade potencial muito alta (4) e alta (5). De acordo com esse autor, o que definiu a classe alta foi o predomínio de Cambissolos em relevo ondulado ( 8 a $20 \%$ de declividade), enquanto que a classe muito alta foi definida pelo predomínio de Neossolos em relevo montanhoso ( 45 a $75 \%$ de declividade).

Por outro lado, em relevos mais suaves, com declividades predominantes abaixo de $30 \%$, e com solos menos suscetíveis ao processo erosivo, observa-se o predomínio das classes de fragilidade potencial baixa e muito baixa. Souza et al. (2005) observaram que $53 \%$ da área da bacia do rio Iraí se encontram com fragilidade potencial baixa (1) a muito baixa (2), sendo que aproximadamente $92 \%$ da área apresentam declividade inferior a $20 \%$. Da mesma forma, Donha et al. (2006) verificaram que $81 \%$ da área do Centro de Estações Experimentais do Canguiri, em Pinhais (PR), apresentam fragilidade potencial baixa (1) a muito baixa (2), havendo ali predomínio de declividades inferiores a $20 \%$ e presença de Latossolos.

Tabela 6. Área (em ha e \%) ocupada por cada classe de fragilidade potencial nos picos Camacuã, Camapuã e Tucum.

Table 6. Area (ha and \%) of each potential fragility class in the Camacuã, Camapuã and Tucum peaks.

\begin{tabular}{lcc}
\hline \multirow{2}{*}{ Fragilidade potencial } & \multicolumn{2}{c}{ Área } \\
\cline { 2 - 3 } & (ha) & $\mathbf{( \% )}$ \\
\hline 3 (Média) & 28 & 3,5 \\
4 (Alta) & 35 & 4,3 \\
5 (Muito alta) & 742 & 92,2 \\
\hline Total & 805 & 100,0 \\
\hline
\end{tabular}

\section{b) Fragilidade emergente}

Com relação à fragilidade emergente (Figura 7), as classes encontradas na área de estudo foram: baixa (2), média (3) e alta (4), as quais foram produtos da fragilidade potencial e do grau de proteção dado ao solo pela vegetação atual, sendo que cada tipo de vegetação protege de maneira diferente o solo. Quanto mais desenvolvida e mais densa essa vegetação, melhor a proteção do solo. Assim, as Florestas Ombrófila Densa Montana, Ombrófila Mista Montana e Floresta Ombrófila Densa Altomontana apresentaram o grau de proteção 1 (muito alta), enquanto o Refúgio Vegetacional e as fases inicial e intermediária da Sucessão Secundária apresentaram o grau de proteção 2 (alta).

A vegetação nessa área, por apresentar alto grau de proteção, amenizou a fragilidade potencial. Ao comparar a tabela 6 (fragilidade potencial) com a tabela 7 (fragilidade emergente) observa-se que a classe muito alta (5) da fragilidade potencial, que ocupava $92 \%$ da área, foi eliminada na fragilidade emergente. $\mathrm{O}$ alto grau de proteção dado pela cobertura vegetal reduziu a fragilidade potencial muito alta (5) para fragilidade emergente média (3) e alta (4) de acordo com o tipo de vegetação. As florestas reduziram para classe emergente média (3), enquanto o refúgio e as sucessões secundárias reduziram para classe emergente alta (4) (Tabela 2). O aumento da classe alta (4), de $4 \%$ da área na fragilidade potencial para $40 \%$ na fragilidade emergente, deve-se à redução da classe de fragilidade potencial muito alta (5), conforme descrito acima. Ainda de acordo com a tabela 2, verifica-se que todas as classes de fragilidade potencial foram reduzidas, em maior ou menor grau, devido à cobertura vegetal, gerando, portanto, classes de fragilidade emergente de menor intensidade. Floriani (2003) também verificou redução em 
locais com fragilidade potencial alta (4) e muito alta (5) e cobertos por vegetação natural, resultando classes de fragilidade emergente de menor intensidade. Em contrapartida, Almeida (2003) observou que o uso agrícola, em função do menor grau de proteção, aumentou a fragilidade potencial, gerando classes de fragilidade emergente mais restritivas. Da mesma forma, Donha et al. (2006) constataram que a fragilidade emergente alta ocorreu em áreas de edificações e circulação. Já a classe de fragilidade emergente média ocorreu predominantemente em áreas de agricultura convencional, ou seja, as atividades humanas aumentaram a fragilidade ambiental, devido à retirada ou diminuição da cobertura vegetal.

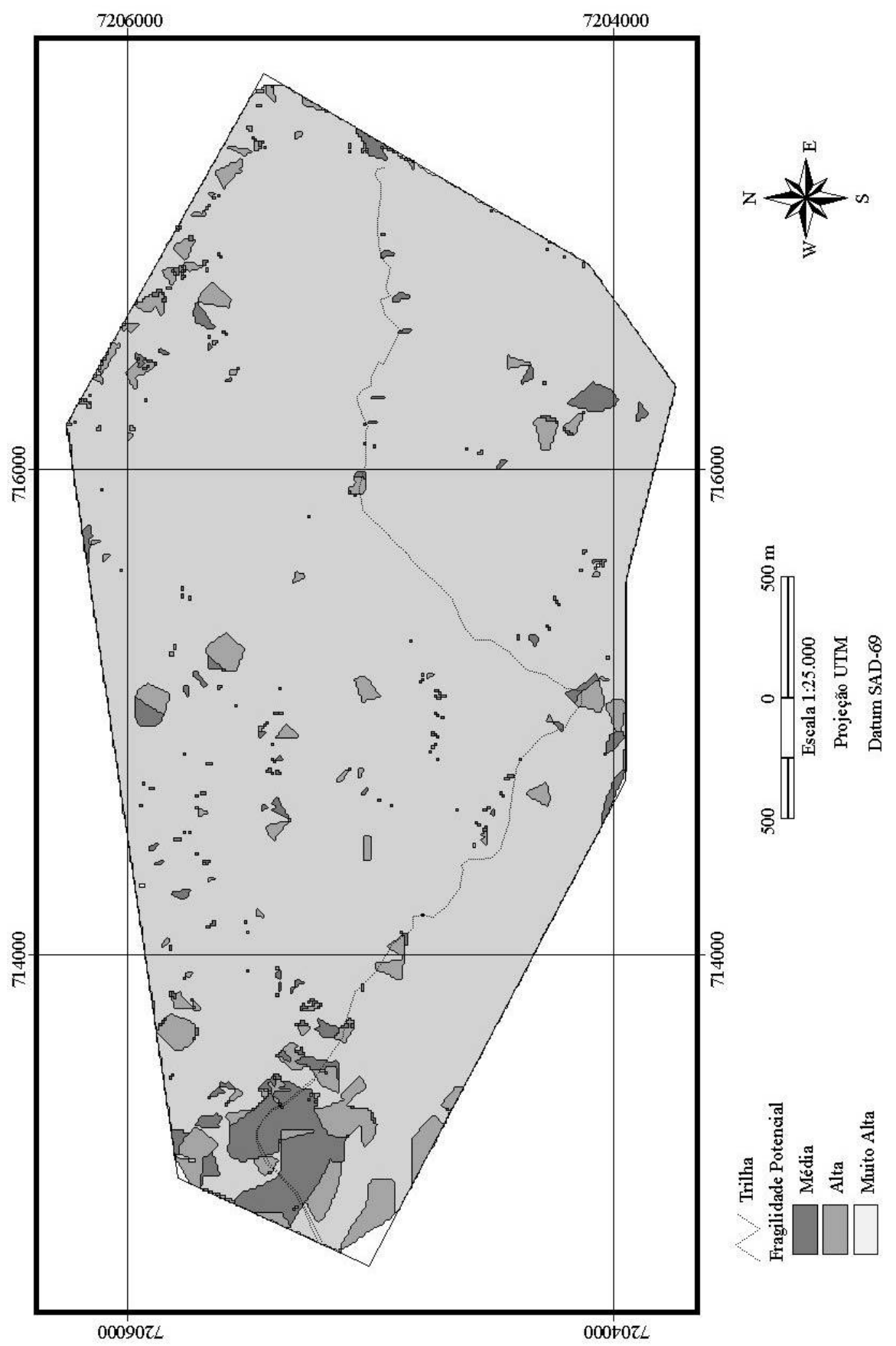

Figura 6. Mapa de fragilidade potencial dos picos Camacuã, Camapuã e Tucum.

Figure 6. Potencial fragility map of the Camacuã, Camapuã and Tucum peaks. 


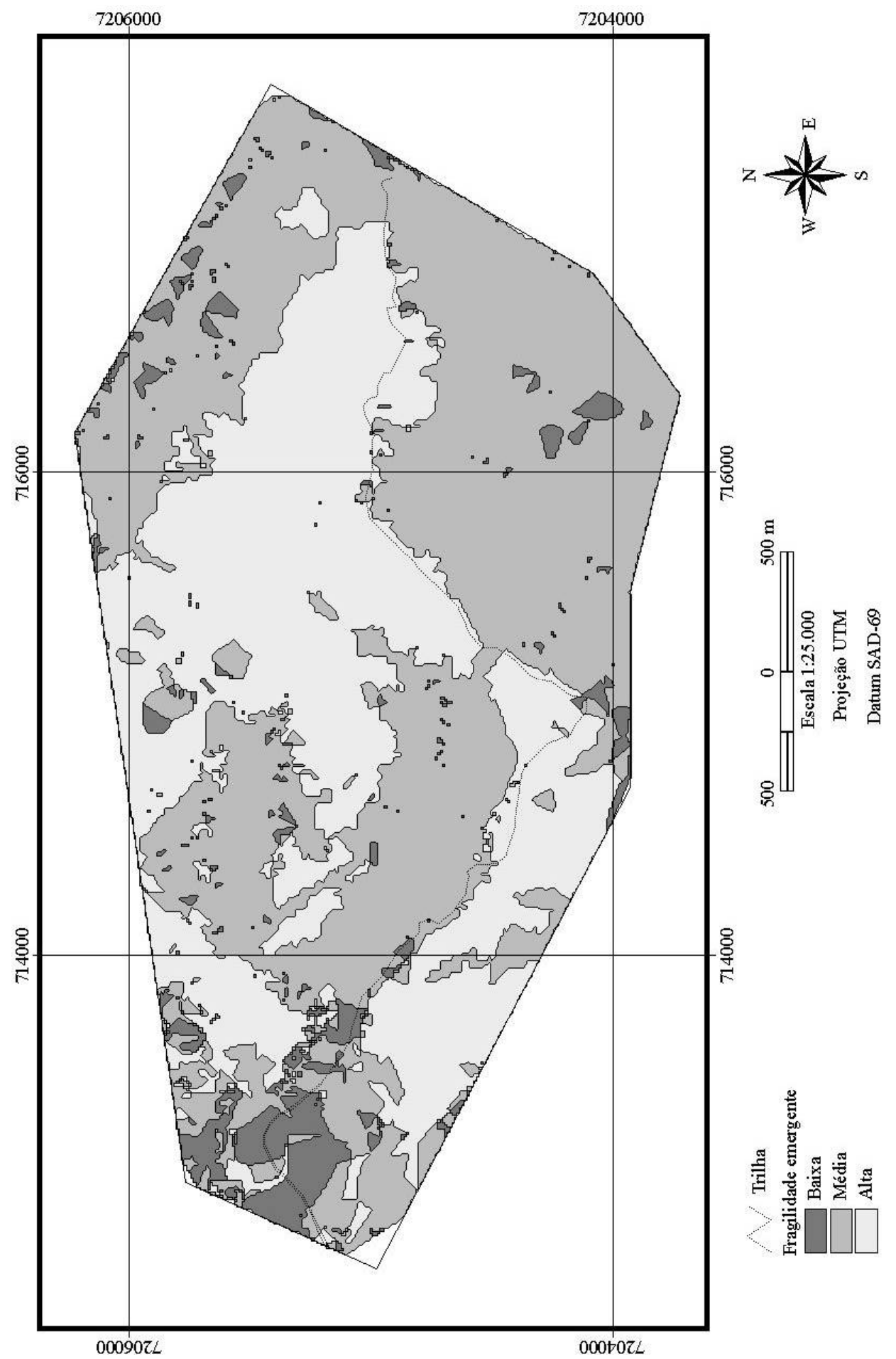

Figura 7. Mapa de fragilidade emergente dos picos Camacuã, Camapuã e Tucum.

Figure 7. Emergent fragility map class of the Camacuã, Camapuã and Tucum peaks.

Esses resultados indicam o importante efeito da cobertura do solo, evidenciando que a remoção da vegetação ocasionará o aumento da fragilidade ambiental. No caso da prática do montanhismo, a 
remoção da vegetação pode ocorrer principalmente nas trilhas e nos locais de acampamento, o que proporcionará, mesmo que pontual, um aumento da fragilidade ambiental.

Tabela 7. Área (em ha e \%) ocupada por cada classe de fragilidade emergente nos picos Camacuã, Camapuã e Tucum.

Table 7. Area (ha and \%) of each emergent fragility class in the Camacuã, Camapuã and Tucum peaks.

\begin{tabular}{lcc}
\hline Fragilidade emergente & Área (ha) & Área (\%) \\
\hline 2 (Baixa) & 45 & 5,6 \\
3 (Média) & 437 & 54,3 \\
4 (Alta) & 323 & 40,1 \\
\hline Total & 805 & 100,0 \\
\hline
\end{tabular}

\section{CONCLUSÕES}

A fragilidade potencial em $92 \%$ da área total foi classificada como muito alta, devido à declividade acentuada predominante e aos solos pouco desenvolvidos, enquanto que $54 \%$ e $40 \%$ da área apresentaram fragilidade emergente média e alta, respectivamente, devido à proteção da cobertura vegetal.

O predomínio de solos pouco desenvolvidos, mesmo em declividades baixas, proporcionou uma elevada fragilidade potencial. No entanto, a cobertura vegetal exerce um papel fundamental na proteção do solo contra a degradação, amenizando a sua fragilidade.

A análise da fragilidade representa um importante instrumento do planejamento ambiental, pois identifica pontos frágeis, fornecendo subsídios para a elaboração de planos de manejo em áreas naturais ou unidades de conservação.

\section{REFERÊNCIAS}

ALMEIDA, L. de. Mudanças técnicas na agricultura: perspectivas da transição agroambiental em Colombo - PR. 290 f. Tese (Doutorado em Meio Ambiente e Desenvolvimento) - Setor de Ciências Agrárias, Universidade Federal do Paraná, Curitiba, 2003.

BIGARElla, J. J. A serra do mar e a porção oriental do estado do Paraná. PARANÁ. Secretaria Estadual de Planejamento/Associação de Defesa e Educação Ambiental. Curitiba, 1978. 248 p.

BARROS, M. I. A. Caracterização da visitação, dos visitantes e avaliação dos impactos ecológicos e recreativos do planalto do parque nacional do Itatiaia.. $121 \mathrm{p}$. Dissertação (Mestrado em Recursos Florestais) - Escola Superior de Agricultura Luiz de Queiroz, Universidade de São Paulo, Piracicaba, 2003.

BRASIL. Represa do Capivari. 1971. 1 mapa: color. Escala 1:50.000.

COGO N. P.; BERTOL, I. O papel das práticas mecânicas e não-mecânicas no controle da erosão hídrica do solo: conceitos e princípios. In: NUERNBERG, N. J. Conceitos e fundamentos do sistema plantio direto. Lages: Sociedade Brasileira de Ciência do Solo. 1998. p. 53 - 75.

COGO, N. P.; LEVIEN, R.; SCHWARZ, R. A. Perdas de solo e água por erosão hídrica influenciadas por métodos de preparo, classes de declive e níveis de fertilidade do solo. Revista Brasileira de Ciência do Solo, Campinas, n. 27, p. 743-753, 2003.

CORDANI, V. G.; GIRARDI, V. A. V. Geologia da folha de Morretes. Boletim da Universidade Federal do Paraná. Geologia, n. 26, 40 p. 1967.

DONHA, A. G.; SOUZA, L. C. de P.; SUGAMOSTO. Determinação da fragilidade ambiental utilizando técnicas de suporte à decisão e SIG. Revista Brasileira de Engenharia Agrícola e Ambiental, Campina Grande, v. 10. n. 1. p. 175-181, 2006.

EMBRAPA. Centro Nacional de Pesquisa de Solos. Sistema brasileiro de classificação de solos. Rio de Janeiro, 1999. $412 \mathrm{p}$. 
FLORIANI, N. Avaliação da fragilidade geossitêmica de uma microbacia sobre geologia cárstica: potencial e limitações. 147 f. Dissertação (Mestrado em Agronomia) - Setor de Ciências Agrárias, Universidade Federal do Paraná, Curitiba, 2003.

GHEZZI, A. O. Avaliação e mapeamento da fragilidade ambiental da bacia do rio Xaxim, baia de Antonina - PR, com o auxílio de geoprocessamento. 49 f. Dissertação (Mestrado em Ciência do Solo) - Setor de Ciências Agrárias, Universidade Federal do Paraná., Curitiba, 2003.

IBGE. Morretes. Rio de Janeiro. 1992a. 1 mapa: color. Escala 1:50.000.

IBGE. Diretoria de Geociências. Departamento de Recursos Naturais e Estudos Ambientais. Manual técnico da vegetação brasileira. Rio de Janeiro, 1992b. 92 p.

IAPAR. Cartas climáticas do Estado do Paraná 1994. Londrina, 1994. 49 p.

ROSS, J. L. S. Análise empírica da fragilidade dos ambientes naturais e antropizados. Revista do Departamento de Geografia, São Paulo, n. 8, 1994.

PARANÁ. Secretaria de Estado do Meio Ambiente e Recursos Hídricos. Resolução SEMA nº 031 de 24 de agosto de 1998, que dispõe sobre o licenciamento ambiental, autorização ambiental, autorização florestal e anuência prévia para desmembramento e parcelamento de gleba rural. Curitiba, 1998.

PARANÁ. Secretaria de Estado do Meio Ambiente e Recursos Hídricos. Mapeamento da Floresta Atlântica do Estado do Paraná. Curitiba, 2002. 2 CD-ROM.

SOUZA, L. C. de P.; SIRTOLI, A. E.; LIMA, M. R. de; DONHA, A. G. Estudo do meio físico na avaliação de bacias hidrográficas utilizadas como mananciais de abastecimento. In: ANDREOLI, C. V.; CARNEIRO, C. (Eds.). Gestão integrada de mananciais de abastecimento eutrofizados. Curitiba: Sanepar/Finep, 2005. p. 123-150.

SPÖRL C.; ROSS J. L. S. Análise comparativa da fragilidade ambiental com aplicação de três modelos. GEOUSP. Espaço e Tempo, São Paulo, n. 15. p. 39-49, 2004.

VASHCHENKO, Y. Caracterização da trilha e o impacto do montanhismo nos picos Camapuã e Tucum - Campina Grande do Sul - PR. 96 f. Dissertação (Mestrado em Ciência do Solo) - Setor de Ciências Agrárias, Universidade Federal do Paraná, Curitiba, 2006. 